\title{
A giant prostatic hyperplasia treated by open surgery
}

This article was published in the following Dove Press journal:

International Journal of General Medicine

4 December 2012

Number of times this article has been viewed

\section{Soichiro Ogawa' \\ Masahiko Manome ${ }^{2}$ \\ Michihiro Yabe ${ }^{2}$ \\ Yoshinobu Kuma² \\ Masaaki Yamaoka' \\ Yuichi Sato' \\ Hidenori Akaihata' \\ Toshiki Oguro' \\ Masao Kataoka' \\ Shin Kumagai' \\ Yoshiyuki Kojima' \\ 'Department of Urology, Fukushima Medical University, Fukushima, Japan; ${ }^{2}$ Department of Urology, Public Soma General Hospital, Soma, Japan}

Correspondence: Soichiro Ogawa Department of Urology, School of Medicine, Fukushima Medical University, I Hikarigaoka, Fukushima 960-1295, Japan

Tel +8I 24547 I316

Fax +8I 245483393

Email soh@fujita-hp.jp
Abstract: We report a rare case of giant prostatic hyperplasia treated by open surgery. A 70-year-old man was suffering from macrohematuria. Computed tomography revealed a markedly enlarged prostate measuring $580 \mathrm{~mL}$. The serum prostate-specific antigen level was $9.430 \mathrm{ng} / \mathrm{mL}$. Prostatic biopsy showed benign prostatic hyperplasia. We perfomed retropubic open prostatectomy, since macrohematuria continued and he was also suffering from lower urinary tract symptoms. The adenoma was completely enucleated in one piece. The removed specimen was $13 \times 11 \times 6 \mathrm{~cm}$ in size and weighed $475 \mathrm{~g}$. Histological examination also demonstrated prostatic fibromuscular hyperplasia. This is the 15 th-heaviest adenoma ever reported in English-language journals. Transurethral surgical techniques or other minimally invasive approaches are performed for patients with small to medium-sized prostates. However, open surgery is recommended for markedly enlarged prostatic hyperplasia.

Keywords: benign prostatic enlargement, benign prostatic hyperplasia, giant, retropubic open prostatectomy

\section{Introduction}

Minimally invasive surgeries for benign prostatic hyperplasia (BPH) have been developed. However, simple open prostatectomy is a recommended method for extremely enlarged prostatic hyperplasia. Here, we report a case with a $475 \mathrm{~g}$ adenoma that was enucleated by retropubic open prostatectomy.

\section{Case report}

A 70-year-old man was admitted to our hospital with a complaint of asymptomatic macrohematuria. Urinalysis showed 50-99 red blood cells/high-power field and $0-1$ white blood cell/high-power field. The result of his urinary cytology was class I. On digital rectal examination, the prostate was found to be grossly enlarged. The serum prostate-specific antigen (PSA) level was $9.430 \mathrm{ng} / \mathrm{mL}$ (normal range 0-4 ng/mL). Cystourethroscopy demonstrated bleeding from the prostatic urethra. A computed tomography scan of his abdomen and pelvis confirmed a considerably heterogeneous enlarged prostate measuring $580 \mathrm{~mL}$. On $\mathrm{T}_{1}$ - and $\mathrm{T}_{2}$-weighted magnetic resonance imaging (MRI), a heterogeneous prostate with sharply marginated nodules was found. The urinary bladder was superiorly pushed (Figure 1). Drip-infusion pyelography showed a normal upper urinary tract with a huge shadow defect of the urinary bladder (Figure 2). A prolonged and narrow prostatic urethra was observed by retrograde vesicourethrography (Figure 3 ). Total international prostate symptom 


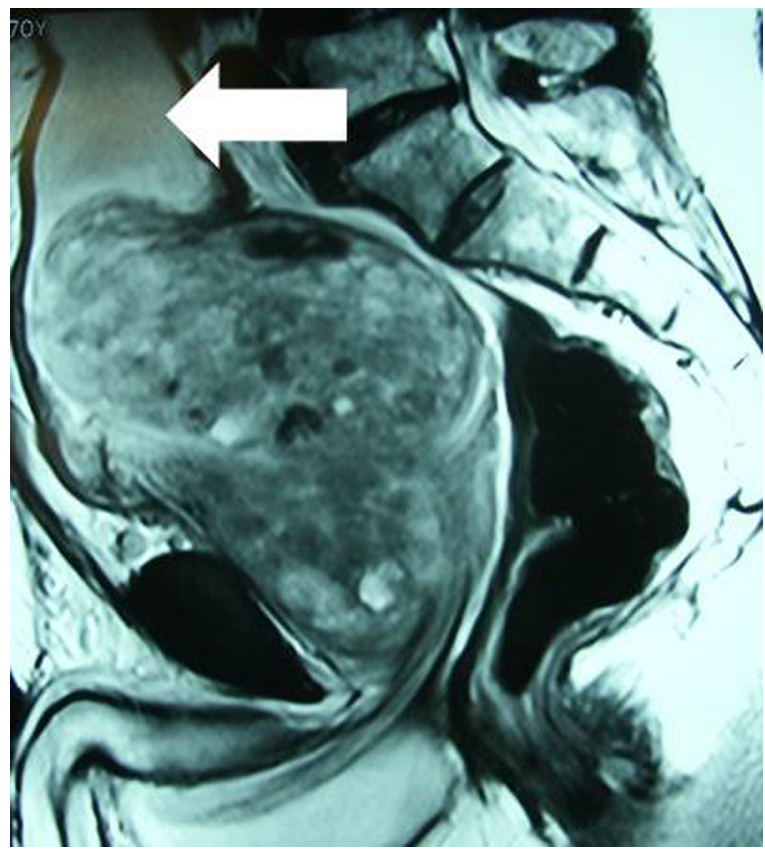

Figure I Magnetic resonance image of a sagittal view revealed a heterogeneous prostate with sharply marginated nodules $\left(\mathrm{T}_{2}\right.$-weighted image).

Notes: The estimated prostate size was $580 \mathrm{~mL}$. The urinary bladder was superiorly pushed (arrow).

score (IPSS) was 14 points, and quality-of-life index was 4. Uroflowmetry (UFM) demonstrated maximum urinary flow rate and average urinary flow rate to be $12.6 \mathrm{~mL} /$ second and $4.8 \mathrm{~mL} /$ second, respectively, with $50 \mathrm{~mL}$ of residual urine volume. Histological examination using transrectal biopsies showed stromal hyperplasia without evidence of malignancy. Thus, he was diagnosed as having giant prostatic hyperplasia and underwent retropubic open prostatectomy through a lower abdominal midline incision. As expected, a markedly enlarged prostate with smooth surface could be seen in the pelvic cavity. The urinary bladder was superiorly displaced. The large adenoma was completely enucleated in one piece. The removed specimen was $13 \times 11 \times 6 \mathrm{~cm}$ in size and weighed $475 \mathrm{~g}$ (Figure 4 ). The operation time was 70 minutes, and blood loss during surgery was $1758 \mathrm{~mL}$ including urine. He did not need a blood transfusion. There was no apparent operative complication. Histological examination demonstrated prostatic fibromuscular hyperplasia. Vesicourethrography at postoperative day 7 showed that the prostatic urethra was obviously wider than before operation. At a month after surgery, improvement was noted in IPSS and UFM. IPSS was 11 points and quality-of-life score was 1 . The results of the UFM were found to be maximum urinary flow rate of $29.2 \mathrm{~mL} / \mathrm{second}$, average urinary flow rate of $13.1 \mathrm{~mL} / \mathrm{second}$, and residual urine of $20 \mathrm{~mL}$. The serum PSA level decreased to $1.520 \mathrm{ng} / \mathrm{mL}$. Macrohematuria disappeared about 2 weeks after operation.

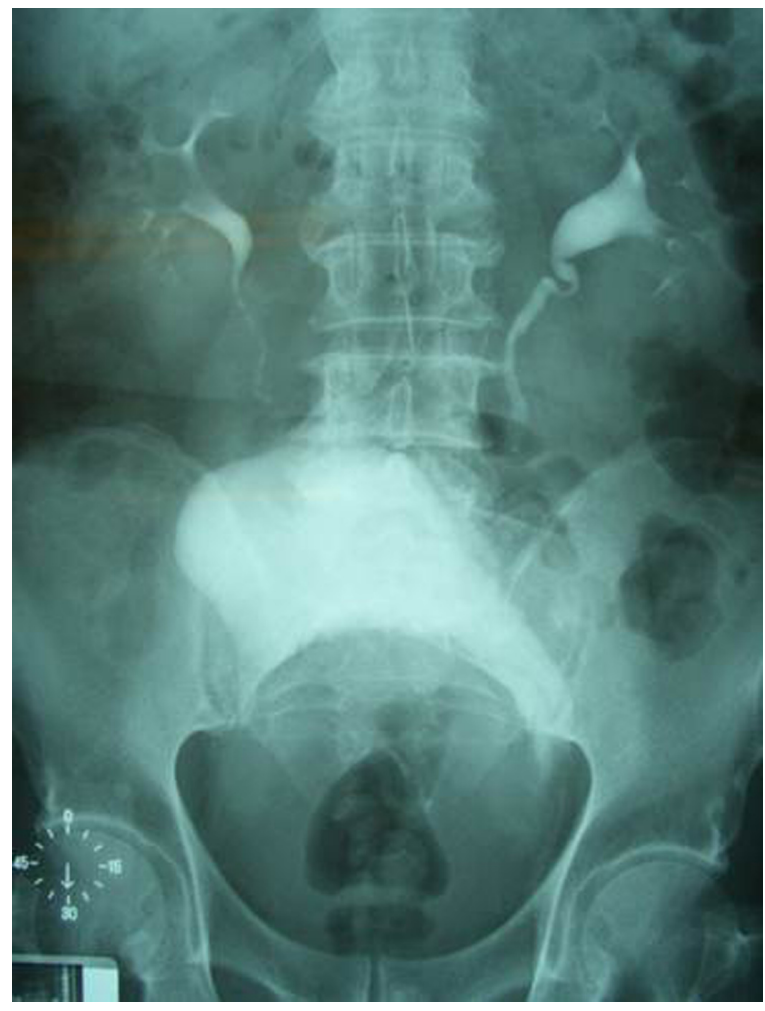

Figure 2 Drip-infusion pyelography demonstrated normal upper urinary tract with a huge shadow defect of the urinary bladder.

\section{Discussion}

$\mathrm{BPH}$ is a pathologic process that can cause lower urinary tract symptoms. Etiology of prostatic growth demonstrates that prostate size increases slowly and steadily with aging. ${ }^{1}$ However, cause and effect links have not been established. The term "giant prostatic hyperplasia" was defined by Fishman and Merrill ${ }^{2}$ as exceeding 500 g. In this case, preoperative MRI revealed a $580 \mathrm{~mL}$ prostate, and actual weight was $475 \mathrm{~g}$.

Although we thought that the increment in the PSA level was probably due to the enlarged prostate adenoma, we performed a biopsy (ten specimens) to rule out prostatic cancer. The result showed no malignant cells.

Surgical treatment for men with BPH is reserved for those who do not respond well to medical therapy or who have complications such as urinary retention. In this case, we considered that there was a surgical indication since macrohematuria continued and he was suffering from lower urinary tract symptoms.

Transurethral resection of the prostate, the gold-standard surgery, is usually applicable to a BPH of up to moderate size $(<50-80 \mathrm{~mL}) .{ }^{3}$ On the other hand, the surgical treatment options for BPH have dramatically changed over the past two decades with the development of minimally invasive 


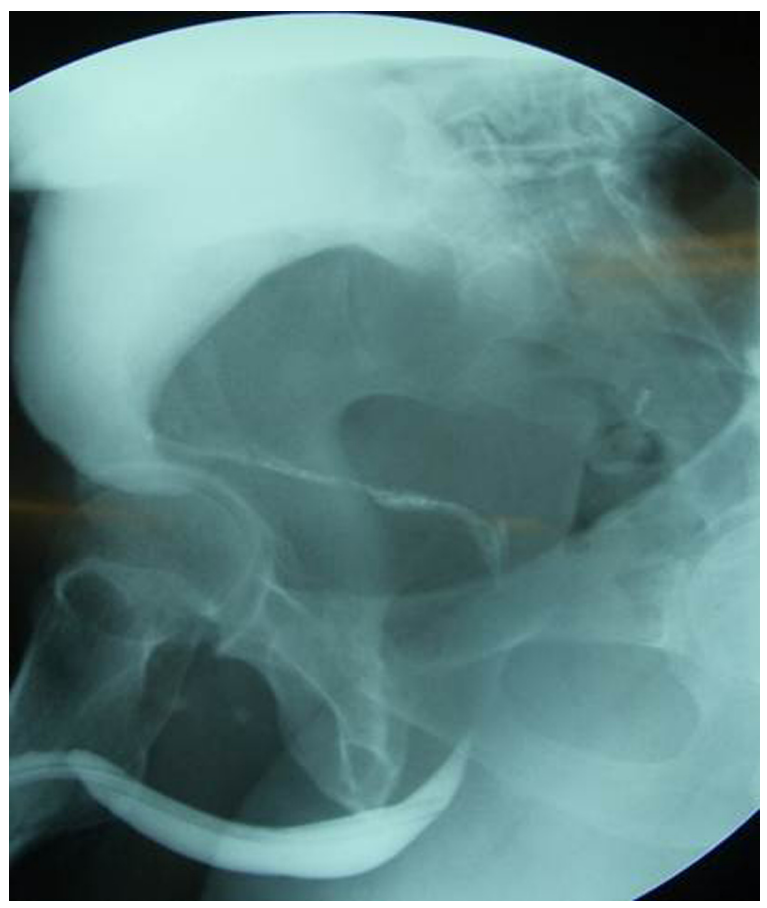

Figure 3 Vesicourethrography showed a prolonged and narrow prostatic urethra.

therapies. They include holmium laser enucleation of the prostate, transurethral electrovaporization of the prostate, transurethral microwave thermotherapy, and others. ${ }^{3}$ However, these techniques are also performed for patients with slightly to moderately enlarged prostates. Rocco et al stated that $100 \mathrm{~g}$ is regarded as the limit of weight for those minimally invasive procedures. ${ }^{4}$ European Association of Urology guidelines also show that open prostatectomy is the treatment of choice for large prostatic glands more than $80-100 \mathrm{~mL}^{5}$ in size.

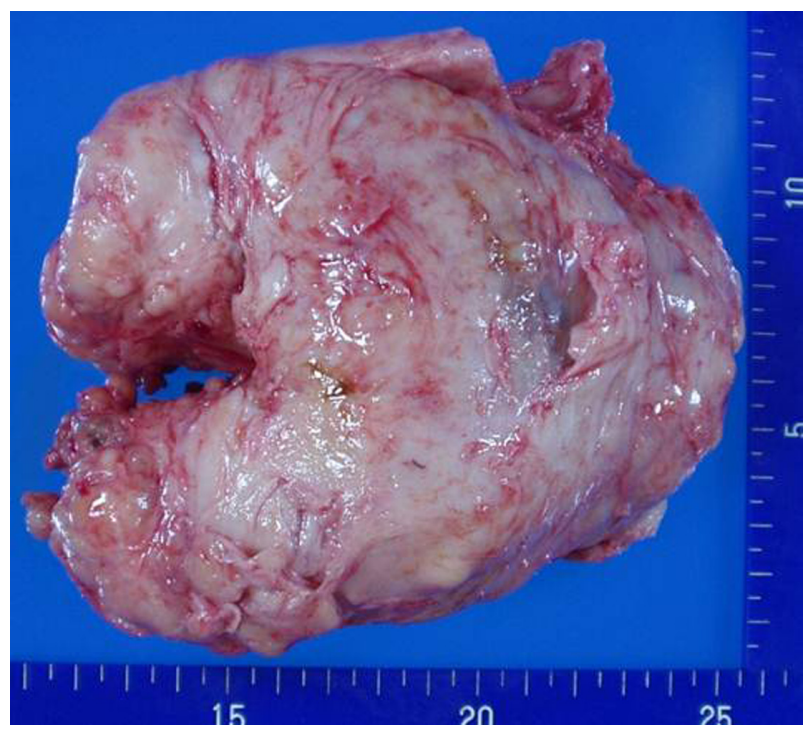

Figure 4 The enucleated specimen was $13 \times 1 \mathrm{I} \times 6 \mathrm{~cm}$ in size and weighed $475 \mathrm{~g}$.
Since 2002, new minimally invasive simple prostatectomy techniques have been reported. McCullough et al published the data that laparoscopic simple prostatectomy for patients with BPH was less invasive compared to open prostatectomy. ${ }^{6}$ They stated that men who underwent laparoscopic prostatectomy had less postoperative catheter time and a shorter hospital stay, although a longer operation time. As for the prostate size, the average preoperative prostatic volume was $111.3 \pm 35.3 \mathrm{~cm}$ in the laparoscopic group. ${ }^{6} \mathrm{It}$ was thought that patients with severely enlarged adenoma were not treated with laparoscopic surgery. In 2008, robotic simple prostatectomy was first reported by Sotelo et al. ${ }^{7}$ Furthermore, Vora et al summarized the studies of robotic simple prostatectomy. ${ }^{8}$ In summary, robotic surgery provides all the merits of laparoscopy with a potentially shorter learning curve. Urinary flow rate, postvoid residual urine, and IPSS scores were also improved by robotic prostatectomy. Operation time and estimated blood loss were similar to those seen in the laparoscopic group. However, Sutherland and colleagues reported that they could not successfully perform robot-assisted simple prostatectomy for a man with severe prostatomegaly $(260 \mathrm{~g})$, although a maximal limit was not placed on prostatic adenoma size during the preoperative evaluation. ${ }^{9}$ These two papers indicated that both laparoscopic and robotic simple prostatectomy would not be feasible for severely enlarged prostate.

Thus, we considered that simple prostatectomy was the recommended treatment for men with enlarged prostate, including giant hyperplasia. In this case, as the estimated prostate volume based on MRI was $580 \mathrm{~mL}$, we performed retropubic open prostatectomy. Operation time was short, and no major complication occurred.

To the best of our knowledge, this is the 15th-heaviest adenoma ever reported in the English-language literature. ${ }^{10}$ Simple open prostatectomy was performed in all 15 cases. We believe that open surgeries are recommended for giant prostatic hyperplasia.

\section{Disclosure}

The authors report no conflicts of interest in this work.

\section{References}

1. Overland GB, Vatten L, Rhodes T, et al. Lower urinary tract symptoms, prostate volume and uroflow in norwegian community men. Eur Urol. 2001;39:36-41.

2. Fishman JR, Merrill DC. A case of giant prostatic hyperplasia. Urology. 1993;42:336-337.

3. Homma Y, Gotoh M, Yokoyama O, et al. Outline of JUA clinical guidelines for benign prostatic hyperplasia. Int J Urol. 2011;18:741-756.

4. Rocco B, Albo G, Coelho R, et al. Recent advances in the surgical treatment of benign prostatic hyperplasia. Ther Adv Urol. 2011;3: $263-272$ 
5. Oelke M, Bachmann A, Descazeaud A, et al. Male lower urinary tract symptoms (LUTS), incl. benign prostatic obstruction (BPO). Available from: http://www.uroweb.org/gls/pdf/12_Male_LUTS_LR\%20May\%20 9th\%202012.pdf. Accessed November 14, 2012.

6. McCullough TC, Heldwein FL, Soon SJ, et al. Laparoscopic versus open simple prostatectomy: an evaluation of morbidity. J Endourol. 2009;23:129-133.

7. Sotelo R, Clavio R, Carmona O, et al. Robotic simple prostatectomy. J Urol. 2008;179:513-515.
8. Vora A, Mittal S, Hwang J, Bandi G. Robot-assisted simple prostatectomy: multi-institutional outcomes for glands larger than 100 grams. $J$ Endourol. 2012;26:499-502.

9. Sutherland DE, Perez DS, Weeks DC. Robot-assisted simple prostatectomy for severe benign prostatic hyperplasia. J Endourol. 2010;25:641-644.

10. Ucer O, Baser O, Gumus B. Giant prostatic hyperplasia: case report and literature review. Dicle Med J. 2011;38:489-491.

\section{Publish your work in this journal}

The International Journal of General Medicine is an international, peer-reviewed open-access journal that focuses on general and internal medicine, pathogenesis, epidemiology, diagnosis, monitoring and treatment protocols. The journal is characterized by the rapid reporting of reviews, original research and clinical studies across all disease areas.
A key focus is the elucidation of disease processes and management protocols resulting in improved outcomes for the patient.The manuscript management system is completely online and includes a very quick and fair peer-review system. Visit http://www.dovepress.com/ testimonials.php to read real quotes from published authors.

Submit your manuscript here: http://www.dovepress.com/international-journal-of-general-medicine-journal 